\title{
Saúde do músico: Perguntas reflexivas dialógicas como estratégia pedagógica
}

\author{
Musician's health: Reflective dialogic questions as a pedagogical strategy \\ Salud del músico: Preguntas dialógicas reflexivas como estrategia pedagógica
}

Recebido: 23/03/2021 | Revisado: 30/03/2021 | Aceito: 05/04/2021 | Publicado: 14/04/2021

\author{
André Leite de Farias \\ ORCID: https://orcid.org/0000-0001-6096-4619 \\ Universidade Católica de Brasília, Brasil \\ E-mail: andreleitedefarias@gmail.com \\ Valdivina Alves Ferreira \\ ORCID: https://orcid.org/0000-0002-2306-7465 \\ Universidade Católica de Brasília, Brasil \\ E-mail: valdivina5784@hotmail.com \\ Luiz Síveres \\ ORCID: https://orcid.org/0000-0003-4735-6066 \\ Universidade Católica de Brasília, Brasil \\ E-mail: luiz.siveres@gmail.com
}

\begin{abstract}
Resumo
O objetivo deste artigo foi desenvolver perguntas reflexivas dialógicas sobre fatores de risco da prática musical como estratégia pedagógica para a prevenção de lesões musculoesqueléticas em estudantes de música. Trata-se de uma pesquisa bibliográfica de revisão, com estratégia exploratória, interpretativa e propositiva. Adicionalmente, com o intuito de subsidiar a discussão, foi realizado levantamento de artigos científicos indexados às plataformas Scielo e Google Scholar. Os resultados foram divididos em três seções. A primeira seção diz respeito às possibilidades e às limitações dos diálogos educacionais na promoção do aprendizado. A segunda seção apresenta breve contextualização a respeito das lesões musculoesqueléticas relacionadas à educação musical. A terceira seção apresenta perguntas reflexivas dialógicas sobre fatores de risco da prática musical como estratégia pedagógica para a prevenção de lesões musculoesqueléticas em estudantes de música. Ao final, concluiu-se que as perguntas reflexivas dialógicas sobre fatores de risco da prática musical podem ser um caminho para o rompimento de barreiras comunicacionais, podem conferir nova dinâmica no fluxo do ensino e aprendizagem sobre a saúde do músico e podem reduzir o número de afastamentos da educação musical por problemas relacionados a lesões musculoesqueléticas.
\end{abstract}

Palavras-chave: Educação; Música; Saúde do estudante.

\begin{abstract}
This paper aimed to develop reflective dialogical questions about risk factors of musical practice as a pedagogical strategy for the prevention of musculoskeletal injuries in music students. This is a literature review, with an exploratory, interpretive and propositional strategy. Additionally, in order to support the discussion, a survey of scientific articles indexed to the Scielo and Google Scholar platforms was carried out. The results were divided into three sections. The first section concerns the possibilities and limitations of educational dialogues in promoting learning. The second section presents a brief contextualization of musculoskeletal injuries related to music education. The third section presents reflective dialogic questions about risk factors of musical practice as a pedagogical strategy for the prevention of musculoskeletal injuries in music students. In the end, it was concluded that reflective dialogic questions can be a way to break communication barriers. They can provide new dynamics in the flow of teaching and learning about the health of the musician and can make it possible to reduce the number of absences from music education due to problems related to musculoskeletal injuries.
\end{abstract}

Keywords: Education; Music; Student health.

\section{Resumen}

Este artículo tuvo como objetivo desarrollar preguntas dialógicas reflexivas sobre los factores de riesgo de la práctica musical como estrategia pedagógica para la prevención de lesiones musculoesqueléticas en estudiantes de música. Se trata de una revisión de la literatura, con una estrategia exploratoria, interpretativa y proposicional. Adicionalmente, con el fin de apoyar la discusión, se realizó una encuesta de artículos científicos indexados a las plataformas Scielo y Google Scholar. Los resultados se dividieron en tres secciones. La primera sección se refiere a las posibilidades y limitaciones de los diálogos educativos para promover el aprendizaje. La segunda sección presenta una breve contextualización de las lesiones musculoesqueléticas relacionadas con la educación musical. La tercera sección presenta preguntas dialógicas reflexivas sobre los factores de riesgo de la práctica musical como estrategia pedagógica para la prevención de lesiones musculoesqueléticas en estudiantes de música. Al final, se concluyó que las preguntas dialógicas reflexivas 
pueden ser una forma de romper las barreras de la comunicación. Pueden aportar nuevas dinámicas en el flujo de enseñanza y aprendizaje sobre la salud del músico y pueden hacer posible reducir el número de ausencias a la educación musical por problemas relacionados con lesiones musculoesqueléticas.

Palabras clave: Educación; Musica; Salud del estudiante.

\section{Introdução}

O diálogo se insere em um cenário abrangente de utilização. Certamente há muito mais a descobrir sobre as maneiras pelas quais o diálogo, em contextos educacionais, contribui para o desenvolvimento das habilidades dos alunos para se comunicar, aprender e raciocinar. Nesse sentido, criar oportunidades efetivas de diálogos educacionais produtivos pode contribuir para garantir, promover e facilitar o aprendizado em diversos cenários, inclusive no contexto da saúde do estudante de música.

A repetição de movimentos, a sobrecarga biomecânica e as posturas antifisiológicas são características da técnica de execução musical. Segundo Steinmetz et al. (2012, p. 1), a performance musical profissional depende de habilidades motoras finas e exige o mais alto controle do sistema musculoesquelético.

A prática musical por várias horas e em alta intensidade, contudo, pode ser prejudicial à saúde do estudante. Ela pode causar sintomas de dor, de tensão e de fadiga e, consequentemente, lesões musculoesqueléticas relacionadas à atividade musical. Nesse contexto, a importância para se haver cuidados com o grupo de estudantes de música está no fato de que as lesões musculoesqueléticas podem causar o afastamento da educação musical (Trelha et al., 2004, p. 69).

Nesse sentido, o desenho da pedagogia, no âmbito da educação musical, deve buscar o incentivo à participação ativa dos alunos e o envolvimento significativo na construção do conhecimento. No contexto da saúde do estudante de música, o diálogo, como estratégia pedagógica, almeja uma educação mais compreensiva, mais crítica e mais reflexiva.

No entanto, para que a compreensão, a crítica e a reflexão aconteçam, é necessário que perguntas recaiam sobre o pensamento do estudante de música e o façam raciocinar sobre os fatores de risco de lesões musculoesqueléticas, sobretudo quanto aos aspectos atinentes à sobrecarga biomecânica e à técnica de execução musical inadequada. O pensar crítico sobre os fatores que aumentam a possibilidade de causar sintomas musculoesqueléticos pode gerar comportamentos preventivos nos estudantes de música.

Assim, o objetivo deste artigo foi desenvolver perguntas reflexivas dialógicas sobre fatores de risco da prática musical como estratégia pedagógica para a prevenção de lesões musculoesqueléticas em estudantes de música.

\section{Metodologia}

Trata-se de uma pesquisa de revisão, com estratégia exploratória, interpretativa e propositiva. Segundo Rother (2007), os artigos de revisão utilizam fontes de informações na literatura, a fim de obter resultados de pesquisas de outros autores, com o objetivo de fundamentar teoricamente um determinado objeto.

Para Vosgerau e Romanowski (2014), os estudos de revisão consistem em organizar, esclarecer e resumir obras existentes. Essas autoras destacam que a análise das publicações pode contribuir na reformulação histórica do diálogo acadêmico por apresentar encaminhamentos fundamentais para sintetizar, avaliar e apontar tendências, bem como para indicar os pontos de fragilidade a fim de favorecer a análise crítica sobre o acumulado da área.

Assim, foi realizada pesquisa bibliográfica não sistemática, com a finalidade de contextualizar o diálogo educacional, fundamentada nas perspectivas de Freire (1987, 2001), Guedes (2007), Lefstein (2010), Síveres (2018) e Mercer, Hennessy e Warwick (2019), bem como para subsidiar a construção das perguntas reflexivas, a partir da perspectiva de Stanhope et al. (2019). 
Para contextualizar a dor e as lesões musculoesqueléticas em estudantes de música, foi realizado um levantamento de artigos científicos na plataforma Scielo, com a utilização do descritor "dor musculoesquelética em músicos". Restringiu-se a busca por ano de publicação: 2006 a 2021. Dos 4 artigos encontrados, optamos por utilizar o de Frank e Mühlen (2007) para subsidiar a discussão sobre a dor musculoesquelética em músicos, uma vez que apresenta diferentes tipos de sintomas musculoesqueléticos e de fatores de risco relacionados à prática musical.

Adicionalmente, foi realizado levantamento de artigos científicos na plataforma Google Scholar, com a utilização do descritor "Music students' health". Restringiu-se a busca por ano de publicação: 2006 a 2021. Classificou-se por relevância. A partir dos 103 resultados obtidos, optamos pela utilização do artigo de Kreutz e Ginsborg (2008). Os motivos pela escolha desse artigo perpassam pelo número de citações, pela relevância e por apresentarem similitudes com o objeto desta pesquisa.

Com fundamento na pesquisa bibliográfica e nas interpretações dos pesquisadores, foram desenvolvidas e apresentadas perguntas reflexivas dialógicas como estratégia pedagógica para a prevenção de lesões musculoesqueléticas em estudantes de música.

\section{Resultados e Discussão}

Os resultados estão divididos em três seções. Na primeira seção, faz-se breves considerações sobre os diálogos educacionais na promoção do aprendizado, com suas possibilidades e limitações. Na segunda seção, introduz-se a contextualização sobre a relação entre as lesões musculoesqueléticas e a educação musical. Na terceira seção, explica-se os benefícios das perguntas reflexivas para a saúde do estudante de música e são apresentadas perguntas reflexivas dialógicas como estratégia pedagógica para o processo de ensino e aprendizado sobre a prevenção de lesões musculoesqueléticas em estudantes da educação musical.

\subsection{Possibilidades e limitações dos diálogos educacionais na promoção do aprendizado}

Buscamos conceituar e relacionar os diálogos educacionais com o conhecimento, indicando possibilidades, limitações e desafios na promoção do aprendizado. A esse respeito, para Síveres (2018, p. 16-18), o diálogo, seja pela compreensão do seu conceito ou pelo exercício de sua prática, assumiu características próprias em cada período da civilização humana. Assim, esse autor destaca que o diálogo foi inserido na trajetória pessoal e social como um procedimento comunicacional, sendo o ambiente educativo um dos espaços apropriados para o seu exercício, fomentando a mediação para a construção do conhecimento e contribuindo com as finalidades do processo educativo.

No âmbito do procedimento comunicacional, Freire (1987, p. 47) enfatiza que "somente o diálogo, que implica um pensar crítico, é capaz também de gerá-lo. Sem ele, não há comunicação, e, sem essa, não há verdadeira educação". Além disso, destaca que o educador não é mais o que apenas educa, "mas o que, enquanto educa, é educado, em diálogo com o educando, que, ao ser educado, também educa" (Freire, 1987, p. 79).

Lefstein (2010, p. 170) assevera que o ideal dialógico é proposto como remédio para a irracionalidade, a falsa consciência, a luta multicultural, os mal-entendidos, a sociedade civil e a ética pós-moderna. $\mathrm{O}$ autor dispõe que, na educação, o diálogo é promovido como um meio de melhorar o ensino e a aprendizagem.

Nesse aspecto, há a possibilidade de o professor assumir a responsabilidade profissional de permitir que alunos sejam tratados e ouvidos igualmente como participantes ativos na sala de aula, uma vez que professores e alunos podem ter um interesse genuíno em explorar as ideias uns dos outros e aprender juntos.

É com esse escopo que se tem defendido a mudança do currículo tradicional e buscado a inserção de projetos nas escolas que propiciem aos educandos o enriquecimento das relações sociais, o exercício do senso crítico, o diálogo, as rodas de discussões em sala de aula e a percepção da realidade social para o engrandecimento da prática educacional cidadã (Rosa, 2007, p. 76). 
Mercer, Hennessy e Warwick (2019, p. 189) entendem que pedagogia dialógica, é, essencialmente, uma abordagem ao ensino baseada no envolvimento ativo e prolongado de alunos e professores na interação falada da sala de aula, de modo que o ensino e a aprendizagem se tornem um esforço coletivo no qual o conhecimento e o entendimento são construídos em conjunto, em vez de a conversa ser usada pelos professores apenas para transmitir o conteúdo do currículo e avaliar sua aquisição pelos alunos.

Com relação a isso, segundo Lefstein (2010, p. 183), o diálogo na escola é orientado e delimitado por conteúdos e objetivos curriculares pré-determinados. Para esse autor, o desafio é: como reformular as principais disciplinas curriculares de maneira que elas sejam favoráveis e estimulem o diálogo? Esse autor argumenta, no entanto, como limitação dos diálogos educacionais, que, ao restringir os tópicos da conversa e direcioná-los para objetivos claros, o currículo delimita ainda mais a amplitude da discussão e a liberdade dos participantes de atrair outras preocupações. Outras limitações dizem respeito à dificuldade de evidenciar o papel do diálogo na aprendizagem.

Lefstein (2010, p. 181) alerta que, embora um movimento dialógico na educação possa incentivar, capacitar e promover o crescimento de alguns estudantes, também pode silenciar e alienar outros. Com relação a esse aspecto, Guedes (2007, p. 24) observa que, apesar de o diálogo enquanto encontro fazer parte de todos os processos educacionais, ele acaba, muitas vezes, servindo de instrumento de dominação do outro, daquilo que ele é, pensa e sente.

Feitas essas considerações acerca do papel dos diálogos educacionais na promoção do aprendizado, e ressalvadas suas limitações, iniciaremos uma breve contextualização das lesões musculoesqueléticas relacionadas à educação musical.

\subsection{O contexto das lesões musculoesqueléticas relacionadas à educação musical}

No contexto da educação musical, Barton e Feinberg (2008, p. 47), nos resultados de sua pesquisa sobre a efetividade de um programa educacional de promoção da saúde e prevenção de lesões musculoesqueléticas em estudantes de música, indicaram a eficácia desse tipo de programa dentro de um currículo acadêmico para estudantes de música. O conteúdo do programa incluiu o fornecimento de informações sobre problemas de saúde comumente vistos em músicos, promoção eficaz da saúde e estratégias preventivas, bem como a aplicação desse conhecimento à reprodução de música e outras ocupações diárias.

É necessário ressaltar, no entanto, que proporções significativas de problemas de saúde entre os alunos de performance musical emergem de disposições gerais, como postura e fadiga, e, portanto, não são específicas para o instrumento tocado (Kreutz; Ginsborg; Williamon, 2008, p. 3).

Desse modo, o conhecimento aprimorado da natureza das disfunções musculoesqueléticas que levam à dor e ao uso excessivo será vital para auxiliar abordagens no tratamento e na prevenção de lesões musculoesqueléticas relacionadas à prática instrumental (Steinmetz et al., 2012, p. 2).

Stanhope et al. (2019, p. 292), em sua revisão sistemática, dispõe que os sintomas musculoesqueléticos são as queixas de saúde mais comuns experimentadas por músicos. Para a autora, esses sintomas podem resultar em uma série de limitações de atividades musicais e, em alguns casos, podem levar os músicos a mudar de carreira ou a parar de tocar permanentemente. A autora destaca que, apesar do grande número de estudos realizados na área de saúde do músico nos últimos trinta anos, é provável que ainda existam subpopulações pouco investigadas e questões de pesquisa sem resposta.

Quanto à atividade musical, cabe destacar que ela exige um empenho excepcional no que se refere à flexibilidade, à condição física individual, à coordenação e à motricidade fina, ao mesmo tempo que a era digital espera do músico um resultado cada vez mais perfeito (Frank \& Mühlen, 2007, p. 188).

No entanto, os músicos, em geral, confiam em sua saúde física e mental para garantir suas posições vocacionais e artísticas, atender às altas demandas do público ou ter sucesso em ambientes competitivos (Rotter et al., 2019, p. 2).

Wu (2007, p. 43) indica que a etiologia das desordens musculoesqueléticas é multifatorial. Nesse sentido, as influências 
do gênero, tempo de experiência com o instrumento, tempo de prática com o instrumento, tipo de instrumento e falta de repouso são alguns dos condicionantes para as lesões musculoesqueléticas.

As diferenças dos locais de sintomas musculoesqueléticos encontrados podem estar relacionadas não só ao maior controle da musculatura em instrumentistas, como indicam Okner, Kernozek e Wade (1997, p. 112), mas também pelo número de horas semanais despendidos para a prática instrumental (Trelha et al., 2004, p. 69). Questionados sobre os tipos de sintomas que apresentam, os músicos mencionam como mais frequente o sintoma de dor, com até $63 \%$ de prevalência (Frank \& Mühlen, 2007, p. 192).

Para Roset-Llobet, Rosinés-Cubells e Saló-Orfila (2000, p. 167) 85,7\% dos músicos acometidos por problemas de saúde apresentam sintomas musculoesqueléticos. Para Pederiva (2005, p. 27), essas evidências não são observadas apenas em músicos de orquestra, mas também em escolas de música.

Segundo Lederman (2003, p. 550), estudantes de música representam um grupo comum para os acometimentos de problemas musculoesqueléticas relacionados à prática instrumental. Desse modo, podemos inferir que devido à alta demanda física na prática instrumental, os estudantes de música possuem alto risco de desenvolver uma variedade de problemas de saúde, entre eles as lesões musculoesqueléticas.

Tendo em vista que os fatores de risco das lesões musculoesqueléticas em estudantes de música estão relacionados à condição física individual, à interação do estudante de música com o instrumento, a aspectos psicossociais e organizacionais e a condições ambientais, o desenvolvimento de perguntas reflexivas dialógicas como estratégia pedagógica, no contexto da prevenção de lesões musculoesqueléticas em estudantes de música, possui relevância científica, pois, além de poder contribuir para a prevenção de danos à saúde do estudante, pode subsidiar a pesquisa em educação musical, em educação pública e em saúde pública.

\subsection{Perguntas reflexivas dialógicas no contexto da prevenção de lesões musculoesqueléticas em estudantes de música}

Os diálogos educacionais possuem relação de colaboração com o processo de ensino e aprendizagem. Assim, deve-se levar em consideração o papel da reflexão individual na extensão e na consolidação desse processo. Ocorre que, para haver reflexão, é necessário que uma pergunta recaia sobre o pensamento do estudante.

Se o estudante conseguir responder a perguntas reflexivas atinentes aos fatores que aumentam a probabilidade de ele sentir dor, tensão ou fadiga musculoesquelética, então ele poderá fazer suposições, inferências e interpretações sobre os comportamentos preventivos que deve adotar para minimizar a chance de ter lesões musculoesqueléticas.

Diante disso, perguntas reflexivas dialógicas relacionadas à condição física individual, à interação com o instrumento, ao ambiente e a fatores psicossociais podem ser utilizadas como estratégia pedagógica para a prevenção de lesões musculoesqueléticas em estudantes de música.

A esse respeito, o Quadro 1 apresenta perguntas reflexivas sobre os fatores de risco de queixas e de lesões musculoesqueléticas relacionados à condição física individual.

Perguntas reflexivas, como as desenvolvidas e apresentadas neste artigo, no contexto de um processo educativo dialógico, possibilitam maior reflexão, por parte do estudante de música, acerca da prevenção de lesões musculoesqueléticas relacionadas à prática musical. 
Quadro 1. Perguntas reflexivas sobre os fatores de risco de queixas e de lesões musculoesqueléticas relacionados à condição física individual.

Por que a minha falta de resistência e força muscular podem desencadear lesões musculoesqueléticas?

Por que a minha má condição física pode desencadear queixas musculoesqueléticas?

Por que a minha pouca flexibilidade pode desencadear queixas musculoesqueléticas?

Por que a minha falta de condicionamento físico pode desencadear queixas musculoesqueléticas?

Por que a minha tensão muscular excessiva pode ser desencadear queixas musculoesqueléticas?

Por que a minha má postura pode desencadear queixas musculoesqueléticas?

Por que o meu cansaço geral pode desencadear queixas musculoesqueléticas?

Por que a minha fadiga muscular pode desencadear queixas musculoesqueléticas?

Fonte: Elaboração própria a partir da pesquisa bibliográfica (2020).

O Quadro 2 apresenta perguntas reflexivas sobre os fatores de risco de queixas e de lesões musculoesqueléticas relacionados à interação entre o estudante de música e o instrumento, ou seja, sobre fatores que aumentam a probabilidade de ocorrência de queixas ou de lesões musculoesqueléticas.

Quadro 2. Perguntas reflexivas sobre os fatores de risco de queixas e de lesões musculoesqueléticas relacionados à interação entre o estudante de música e o instrumento.

Por que longas sessões de prática instrumental podem desencadear queixas musculoesqueléticas?

Por que a mudança em minha rotina de prática instrumental pode desencadear queixas musculoesqueléticas?

Por que o aumento ou a diminuição repentina nas horas de prática instrumental podem desencadear queixas musculoesqueléticas?

Por que o aquecimento insuficiente antes do estudo pode desencadear queixas musculoesqueléticas?

Por que intervalos de descanso insuficientes podem desencadear queixas musculoesqueléticas?

Por que poucas pausas ao tocar podem desencadear queixas musculoesqueléticas?

Por que a técnica de execução inadequada pode desencadear queixas musculoesqueléticas?

Por que a execução de repertório musical difícil pode desencadear queixas musculoesqueléticas?

Por que a realização do mesmo movimento repetidamente pode desencadear queixas musculoesqueléticas?

Por que o transporte do instrumento pode desencadear queixas musculoesqueléticas?

Por que a variação no funcionamento e / ou mau funcionamento do instrumento pode desencadear queixas musculoesqueléticas?

Por que a configuração do instrumento pode desencadear queixas musculoesqueléticas?

Fonte: Elaboração própria a partir da pesquisa bibliográfica (2020).

Ressalta-se que o desenvolvimento dessas perguntas reflexivas dialógicas possui como finalidade o apoio à reflexão do estudante e visa a subsidiar a prevenção de agravos à saúde do estudante de música. Contudo, consideramos um gatilho e não um rol exaustivo de perguntas. 
O Quadro 3 apresenta perguntas reflexivas sobre os fatores de risco de queixas e de lesões musculoesqueléticas relacionados ao ambiente.

Quadro 3. Perguntas reflexivas sobre os fatores de risco de queixas e de lesões musculoesqueléticas relacionados ao ambiente. Por que cadeiras inadequadas, utilizadas para sentar enquanto toco, podem desencadear queixas musculoesqueléticas?

Por que más condições ambientais para tocar podem desencadear queixas musculoesqueléticas?

Por que o local de prática / ensaio pode desencadear queixas musculoesqueléticas?

Fonte: Elaboração própria a partir da pesquisa bibliográfica (2020).

Nesse contexto, Freire (2001, p. 83) defende uma pedagogia crítico-dialógica, uma pedagogia da pergunta. Esse autor aponta que a escola pública ideal é aquela onde tem lugar de destaque a apreensão crítica do conhecimento significativo por meio da relação dialógica, é aquela que estimula o aluno a perguntar, a criticar e a criar.

O Quadro 4 apresenta um rol exemplificativo de perguntas reflexivas sobre os fatores de risco de queixas e de lesões musculoesqueléticas relacionados a aspectos psicossociais.

Quadro 4. Perguntas reflexivas sobre os fatores de risco de queixas e de lesões musculoesqueléticas relacionados a aspectos psicossociais.

Por que problemas emocionais podem desencadear queixas musculoesqueléticas?

Por que o estresse e / ou ansiedade podem desencadear queixas musculoesqueléticas?

Por que a depressão pode desencadear queixas musculoesqueléticas?

Por que a insatisfação no trabalho pode desencadear queixas musculoesqueléticas?

Por que a aspiração de desempenho próprio pode desencadear queixas musculoesqueléticas?

Por que a pressão dos professores pode desencadear queixas musculoesqueléticas?

Fonte: Elaboração própria a partir da pesquisa bibliográfica (2020).

O que se espera é que, por meio das perguntas reflexivas dialógicas, o estudante possa raciocinar sobre as próprias particularidades e sobre as peculiaridades de sua prática musical para que, efetivamente, possa aprender a adotar comportamentos preventivos.

Segundo Síveres (2018, p. 23), o diálogo, no processo pedagógico, é essencialmente criativo, porque gera novas palavras, é reflexivo, porque envolve a formulação de novas perguntas, e é propositivo, porque encaminha novas respostas. Diante disso, segundo esse autor, o diálogo é uma Paideia, isto é, um processo de formação integral e um procedimento de formação integrador, que educa perguntando e pergunta pelo sentido da educação. E ele destaca que a pergunta é sempre feita na expectativa de mergulhar num problema e este é problematizado por meio de uma pergunta.

Desse modo, as perguntas reflexivas dialógicas podem demonstrar claramente a perspectiva de quem sofre com as lesões musculoesqueléticas relacionadas à prática musical: o estudante.

O Quadro 5, por fim, apresenta perguntas reflexivas dialógicas gerais sobre os fatores de risco de queixas e de lesões musculoesqueléticas. 
Quadro 5. Perguntas reflexivas gerais sobre os fatores de risco de queixas e de lesões musculoesqueléticas.

Por que a falta de entendimento da tensão física pode desencadear queixas musculoesqueléticas?

Por que a falta de conhecimentos básicos de anatomia / fisiologia pode desencadear queixas musculoesqueléticas?

Por que a perda de concentração pode desencadear queixas musculoesqueléticas?

Por que o descanso insuficiente pode desencadear queixas musculoesqueléticas?

Por que a atitude "sem dor, sem ganho" pode desencadear queixas musculoesqueléticas?

Por que sintomas musculoesqueléticos, quando considerados parte normal da atividade musical, podem desencadear queixas musculoesqueléticas?

Por que a escola deveria empregar um especialista para lidar com esses sintomas musculoesqueléticos que sinto?

Por que o conselho de um profissional de saúde em relação à posição de tocar, com a finalidade de evitar as queixas musculoesqueléticas, poderia mudar meu comportamento de estudo?

Por que estou preocupado com a dor relacionada à prática instrumental?

Por que acredito que não passarei pela dor relacionada à prática instrumental?

Por que a dor relacionada à prática instrumental poderia levar a lesões graves?

Fonte: Elaboração própria a partir da pesquisa bibliográfica (2020).

Ainda é cedo para avaliar em que medida as perguntas reflexivas dialógicas podem provocar um maior engajamento dos estudantes nos aspectos que contribuem, como estratégia pedagógica, para a prevenção de lesões musculoesqueléticas relacionadas à atividade musical.

\section{Considerações Finais}

Perguntas reflexivas dialógicas sobre fatores de risco da prática musical podem ser um caminho para o rompimento de barreiras comunicacionais, podem conferir nova dinâmica no fluxo do ensino e aprendizagem sobre a saúde do músico e podem reduzir o número de afastamentos da educação musical por problemas relacionados a lesões musculoesqueléticas.

As soluções que têm sido propostas para resolver lesões musculoesqueléticas relacionadas à educação musical carecem ainda de estratégias pedagógicas de prevenção capazes não só de torná-las mais presentes na educação, mas de aprimorá-las a partir da incorporação de novas metodologias, boas práticas e soluções alternativas que podem ser construídas em um contexto de diálogo institucionalizado das partes interessadas.

Assim, sugere-se que outras pesquisas sejam realizadas com a finalidade de verificar se a aplicação das perguntas reflexivas dialógicas desenvolvidas e apresentadas neste artigo podem contribuir para o aprendizado sobre prevenção de lesões musculoesqueléticas no contexto da educação musical.

Pesquisas futuras nessa área poderiam evidenciar a influência dessas perguntas no aprendizado efetivo sobre prevenção de lesões musculoesqueléticas no estudante de música, bem como otimizar programas sobre a saúde do músico no contexto escolar. 
Research, Society and Development, v. 10, n. 4, e37810414177, 2021

(CC BY 4.0) | ISSN 2525-3409 | DOI: http://dx.doi.org/10.33448/rsd-v10i4.14177

\section{Referências}

Barton, R., \& Feinberg, J. (2008). Effectiveness of an educational program in health promotion and injury prevention for Freshman music majors. Medical Problems Performing Artists. 23(2):47-53.

Frank, A, \& Mühlen, C. A. (2007). Queixas Musculoesqueléticas em Músicos: Prevalência e Fatores de Risco. Rev Bras Reumatol, 47(3), 188-196.

Freire, P. (1987). Pedagogia do Oprimido. (17a ed.), Paz e Terra.

Freire, P. (2001). Pedagogia da Autonomia: saberes necessários à prática educativa. (20a ed.), Paz e Terra, 2001.

Guedes, E. C. (2007). Alteridade e Diálogo: uma meta-arqueologia da educação a partir de Emmanuel Lévinas e Paulo Freire. Tese (Doutorado em Educação). João Pessoa (PB): UFPB.

Kreutz, G., Ginsborg, J., \& Williamon, A. (2008). Music students' health problems and health-promoting behaviours. Medical Problems of Performing Artists. 23(1), 3-11.

Lederman, R. J. (2003). Neuromuscular and musculoskeletal problems in instrumental musicians. Muscle \& Nerve. 27(5), 549-561.

Lefstein, A. (2010). More helpful as problem than solution: some implications of situating dialogue in classroom. In: LITTLETON, Karen e HOWE, Christine. Educacional Dialogues: understanding and promoting productive interaction. Routledge.

Mercer, N., Hennessy, S., \& Warwick, P. (2019). Dialogue, Thinking Together and Digital Technology in the Classroom: Some Educational Implications of a Continuing Line of Inquiry. International Journal of Educational Research.

Okner, M. A. O., Kernozek, T., \& Wade, M. G. (1997). Chin rest pressure in violin players: musical repertoire, chin rests, and shoulder pads as possible mediators. Medical Problems of Performing Artists, 12(4), 112-121.

Pederiva, P. L. M. (2005). O corpo no processo de ensino-aprendizagem de instrumentos musicais: percepção de professores. Dissertação (Mestrado em Educação). Brasília (DF): UCB.

Rosa, B. C. (2007). Educação para a cidadania: uma exigência constitucional para a efetivação da democracia no Brasil. Dissertação (Mestrado em Direito Constitucional). Fortaleza (CE): Unifor.

Roset-Llobet, J., Rosinés-Cubells, D., \& Saló-Orfila, J. M. (2000). Identification of risk factors for musicians in Catalonia (Spain). Medical Problems of Performing Artists, 15(4), 167-74.

Rother, E. T. (2007). Revisão sistemática X revisão narrativa. Acta Paulista de Enfermagem, 20(2), v-vi.

Rotter, G. et al. (2019). Musculoskeletal disorders and complaints in professional musicians: a systematic review of prevalence, risk factors, and clinical treatment effects. International Archives of Occupational and Environmental Health.

Síveres, L., \& Vasconcelos, I. C. O. (2018). DIÁLOGO: um processo educativo. Cidade Gráfica Editora.

Stanhope, J. et al. (2019). Have musicians' musculoskeletal symptoms been thoroughly addressed? A systematic mapping review. International Journal of Occupational Medicine and Environmental Health, 32(3):291 - 331.

Steinmetz, A. et al. (2012). Playing-related musculoskeletal disorders in music students-associated musculoskeletal signs. European Journal of Physic and Rehabilitation Medicine. 48.

Trelha, C. S. et al. (2004). Arte e Saúde: Freqüência de sintomas músculo-esqueléticos em músicos da orquestra sinfônica da Universidade Estadual de Londrina. Semina: Ciências Biológicas e da Saúde. 25, 65-72.

Vosgerau, D. S. A. R., \& Romanowski, J. P. (2014). Revista Diálogo Educacional. 14(41), 165-189.

Wu, S. J. (2007). Occupational Risk Factors for Musculoskeletal Disorders in Musicians: A Systematic Review. Medical Problems of Performing Artists. 22(2), 43-51. 